\title{
Correlation between Serum Retinol and $\alpha$-Tocopherol Levels in Centenarians
}

\author{
Giorgio BASILE ${ }^{1}$, Sebastiano GANGEMI ${ }^{2}$, Claudia Lo BALBO ${ }^{1}$, Antonella MENTO ${ }^{1}$, \\ Claudio NicITA-MAURO ${ }^{1}$, Giancarlo CRISAFULli ${ }^{3}$, Rosaria A. MERENDINO ${ }^{2}$, Riccardo IENTILE ${ }^{3}$ \\ and Vittorio NiCITA-MAURO ${ }^{1}$ \\ ${ }^{1}$ Chair of Geriatrics and Division of Geriatric Medicine, ${ }^{2}$ School of Allergy and Clinical Immunology and \\ ${ }^{3}$ Department of Biochemical, Physiological and Nutritional Sciences, University of Messina, Messina, Italy
}

(Received November 12, 2002)

\begin{abstract}
Summary Recent evidence indicates that longevity may be achieved when efficient defence mechanisms against oxidative stress, infections, neoplasia, and cardiovascular events are preserved. Centenarians represent an example of "successful aging," and the aim of this study was to evaluate serum levels of vitamins A and E, which represent two important nonenzymatic antioxidant defence systems, and their correlation in 16 healthy centenarians and two groups of control subjects. Centenarians showed normal values of retinol $(450.9 \pm 240.3 \mathrm{ng} / \mathrm{mL})$ and $\alpha$-tocopherol $(9220.2 \pm 3410.9 \mathrm{ng} / \mathrm{mL})$. Moreover, a significant direct correlation between the two vitamins was observed in centenarians (Rho $=0.715$, $p=0.0056)$, such as in younger control subjects $(\mathrm{Rho}=0.618, p=0.0168)$, but not in older control subjects. We assume that the preservation of normal values and the correlation between vitamin $\mathrm{A}$ and $\mathrm{E}$ concentrations protects centenarians against oxidative stress and contributes to their extreme longevity.
\end{abstract}

Key Words centenarians, retinol, $\alpha$-tocopherol, oxidative stress, aging

Oxidative stress plays an important role in the aging process and in the development of several diseases; especially, cardiovascular diseases, dementia, and cancer (1). The oxidative damage in aerobic organisms is obstructed by antioxidant defence systems, including antioxidant and repairing enzymes and antioxidant vitamins. The lipid-soluble vitamins $\mathrm{A}$ and $\mathrm{E}$ represent two important nonenzymatic antioxidant defence systems and play a role in the normal function of immune systems in terms of the prevention of cardiovascular diseases and of some types of cancer. Centenarians represent a living example of extreme longevity and so-called "successful aging;" the result of a favourable interaction between genetic and enviromental factors.

The aim of this study was to evaluate serum levels and the relationship between concentrations of vitamin $\mathrm{A}$ and vitamin $\mathrm{E}$ in healthy centenarians as compared to adults and older healthy subjects.

The study population consisted of a group of 16 healthy centenarians ( 4 men and 12 women, aged between 100 and $105 \mathrm{y}$ ) living in Messina (a municipality of Eastern Sicily, Italy) and two groups of healthy subjects selected from the community (group A: 16 subjects, 6 men and 10 women aged between 45 and $64 \mathrm{y}$, mean age of $54.06 \pm 6.49 \mathrm{y}$; group B: 16 subjects, 6 men and 10 women, aged between 65 and $85 \mathrm{y}$, mean age of $73.69 \pm 6.13 \mathrm{y}$ ).

They were interviewed, and clinically and functionally evaluated.
From all subjects, blood samples were obtained in the morning between 08:00 and 10:00, from a large antecubital vein. A biochemical panel on fresh blood samples was performed. Plasma was separately stored in eppendorf tubes and kept at $-80^{\circ} \mathrm{C}$ until analysis.

Levels of retinol and $\alpha$-tocopherol were assayed by high-performance liquid chromatography (HPLC) (2) using an HPLC system with a reversed phase column (Chromat III, Bio-Rad Laboratories, Munchen-D, Germany).

Differences in vitamin levels were assessed by oneway analysis of variance (ANOVA) and the StudentNewman-Keults test. Data are expressed as mean \pm standard deviation, and correlation coefficients were calculated using the Spearman rank order correlation index. A value of $p<0.05$ was considered significant.

As a nutritional parameter the concentrations of albumin were measured. Serum levels of albumin were within the normal range in the centenarians $(38.7 \pm 4.9 \mathrm{~g} / \mathrm{L})$ and control groups (group A: $41.1 \pm 4.0 \mathrm{~g} / \mathrm{L}$; group B: $40.8 \pm 4.0 \mathrm{~g} / \mathrm{L}$ ).

Our results show that centenarians had an average level of retinol $(450.9 \pm 240.3 \mathrm{ng} / \mathrm{mL})$ and $\alpha$-tocopherol $(9220.2 \pm 3410.0 \mathrm{ng} / \mathrm{mL})$, not significantly different from that determined for groups A (retinol: 551.5 $125.1 \mathrm{ng} / \mathrm{mL} ; \alpha$-tocopherol: $10795.5 \pm 4222.7 \mathrm{ng} / \mathrm{mL}$ ) and B (retinol: $496 \pm 92.3 \mathrm{ng} / \mathrm{mL} ; \alpha$-tocopherol: 8607.9 $\pm 3918.4 \mathrm{ng} / \mathrm{mL}$ ). It is interesting to observe that the centenarians had higher vitamin E levels, even if not significantly, as compared to the older control subjects.

Data on plasma concentrations of retinol and $\alpha$-toco- 

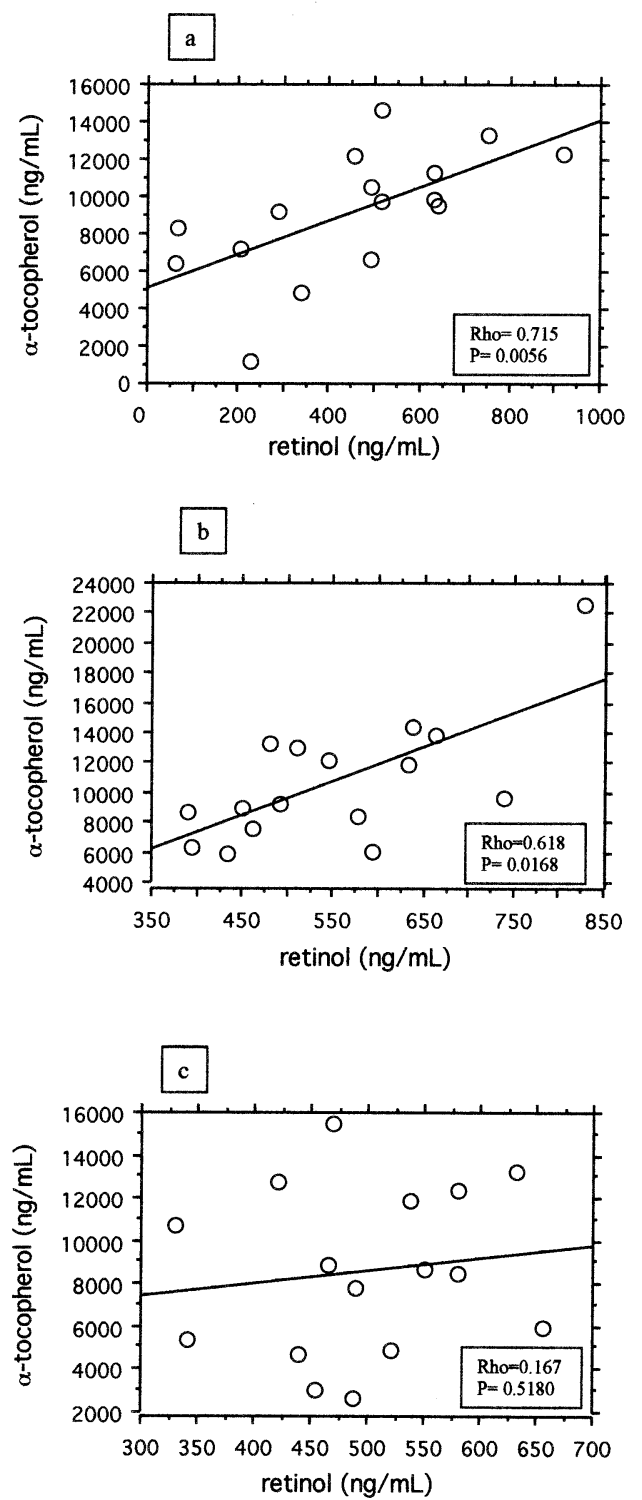

Fig. 1. Correlation between retinol and $\alpha$-tocopherol in centenarians (1a), group A(1b), and group B (1c). Data points are from single measurements.

pherol in elderly people are sparse and contrasting. In the healthy elderly participants of the Framingham Heart Study (3), the percentile ranges of retinol, tocopherol, and carotenoid were comparable with those established in younger cohorts. Moreover, elderly women had significantly higher plasma concentrations of vitamin $\mathrm{E}$ than elderly men. In institutionalized elderly people, most vitamins and trace elements were significantly negatively correlated with age (4). A recent study showed that levels of nonenzymatic antioxidant components decline during aging, but centenarians have shown higher plasma levels of lipid-soluble vitamins A and E than other elderly subjects (5).

Moreover, we found a significant direct correlation between retinol and $\alpha$-tocopherol concentrations in centenarians (Rho $=0.715, p=0.0056$ ) (Fig. 1a) and the younger control group (Rho=0.618, $p=0.0168$ ) (Fig. 1b). On the contrary, this correlation disappeared in the older control group ( $\mathrm{Rho}=0.167, p=0.5180$ ) (Fig. 1C), probably as a consequence of the major reduction in $\alpha$-tocopherol levels in respect to the younger control group.

Vitamin E directly scavenges reactive oxygen species and protects cells from the peroxidation of polyunsatured fatty acids in cellular and subcellular membrane phospholipids. Vitamin A is not a direct scavenger, but plays a role in preventing radical-induced cytotoxicity by reducing nitric oxide $(\mathrm{NO})$ generation through inducible-NO-Synthase (6).

We assume that the preservation of normal levels and maintenance of a significant direct correlation between the two vitamins contributes to extreme longevity.

The values of the albumin concentrations showed that the centenarians involved in this study were wellnourished, and that the maintenance of a normal nutritional status is most important for the healthcare of centenarians. Another useful nutritional parameter recently investigated in centenarians (7) is the retinolbinding protein (RBP), a rapid turnover protein that is an indicator of vitamin A nutritional state.

Plasma concentrations of vitamins are influenced by food intake and lifestyle. Therefore, longitudinal studies will be necessary to clarify the role of antioxidant vitamins in the aging process and longevity.

\section{REFERENCES}

1) Ashok BT and Ali R. 1999. The aging paradox: the free radical theory of aging. Exp Gerontol 34: 293-303.

2) Ihara H, Ishigaki H, Shino Y, Hashizume N, Takase M, Nagao J, Sumiyama Y. 2000. Clinical and analytical evaluation of the simultaneous HPLC assay of retinol and $\alpha$-tocopherol. J Nutr Sci Vitaminol 46: 257-262.

3) Vogel S, Contois JH, Tucker KL, Wilson PW, Shaefer EJ, Lammi-KeefeJ. 1997. Plasma retinol and plasma lipoprotein tocopherol and carotenoid concentrations in healthy elderly partecipants of the Framingham Heart Study. Am J Clin Nutr 66: 950-958.

4) Monget AL, Galan P, Preziosi P, Keller H, Bourgeois C, Arnaud J, Favier A, Hercberg S. 1996. Micronutrient status in elderly people. Geriatrie/Min. Vit. Aux Network. Int J Vitam Nutr Res 66: 71-76.

5) Mecocci P, Polidori MC, Troiano L, Cherubini A, Cecchetti R, Pini G, Straatman M, Monti D, Stahl W, Sies H, Franceschi C, Senin U. 2000. Plasma antioxidants and longevity: a study on healthy centenarians. Free Radic Biol Med 28: 1243-1248.

6) Fang YZ, Yang S, Wu G. 2002. Free radicals, antioxidants, and nutrition. Nutrition 18: 872-879.

7) Arai Y, Hirose N, Yamamura K, Shimizu K, Takayama M, Ebihara Y, Osono Y. 2001. Serum insulin-like growth factor-1 in centenarians: implications of IGF-1 as a rapid turnover protein. J Gerontol A Biol Sci Med Sci 56: M79-M82. 